\title{
Adult Lymphoma
}

National Cancer Institute

\section{Source}

National Cancer Institute. Adult Lymphoma. NCI Thesaurus. Code C7587.

A lymphoma that occurs in adults. 